\title{
Availability, prices, and affordability of selected essential cancer medicines in a middle-income country - the case of Mexico
}

Daniela Moye-Holz ${ }^{1 *}$ (D) Margaret Ewen ${ }^{2} \mathbb{D}$, Anahi Dreser $^{3}$ (D), Sergio Bautista-Arredondo ${ }^{3} \mathbb{D}$, Rene Soria-Saucedo ${ }^{4} \mathbb{D}$, Jitse P. van Dijk ${ }^{1}$, Sijmen A. Reijneveld ${ }^{1}$ (B) and Hans V. Hogerzeil ${ }^{1}$ (B)

\begin{abstract}
Background: More alternatives have become available for the diagnosis and treatment of cancer in low- and middle-income countries. Because of increasing demands, governments are now facing a problem of limited affordability and availability of essential cancer medicines. Yet, precise information about the access to these medicines is limited, and the methodology is not very well developed. We assessed the availability and affordability of essential cancer medicines in Mexico, and compared their prices against those in other countries of the region.

Methods: We surveyed 21 public hospitals and 19 private pharmacies in 8 states of Mexico. Data were collected on the availability and prices of 49 essential cancer medicines. Prices were compared against those in Chile, Peru, Brazil, Colombia and PAHO's Strategic Fund.

Results: Of the various medicines, mean availability in public and private sector outlets was 61.2 and $67.5 \%$, respectively. In the public sector, medicines covered by the public health insurance "People's Health Insurance" were more available. Only seven (public sector) and five (private sector) out of the 49 medicines were considered affordable. Public sector procurement prices were $41 \%$ lower than in other countries of the region.

Conclusions: The availability of essential cancer medicines, in the public and private sector, falls below World Health Organization's $80 \%$ target. The affordability remains suboptimal as well. A national health insurance scheme could serve as a mechanism to improve access to cancer medicines in the public sector. Comprehensive pricing policies are warranted to improve the affordability of cancer medicines in the private sector.
\end{abstract}

Keywords: Availability, Affordability, Prices, Essential cancer medicines, Mexico

\footnotetext{
* Correspondence: danymoyeholz@gmail.com

'Department of Community and Occupational Medicine, University Medical

Center Groningen, University of Groningen, Hanzeplein 1, 9713 GZ Groningen, The Netherlands

Full list of author information is available at the end of the article
}

(C) The Author(s). 2020 Open Access This article is licensed under a Creative Commons Attribution 4.0 International License, which permits use, sharing, adaptation, distribution and reproduction in any medium or format, as long as you give appropriate credit to the original author(s) and the source, provide a link to the Creative Commons licence, and indicate if changes were made. The images or other third party material in this article are included in the article's Creative Commons licence, unless indicated otherwise in a credit line to the material. If material is not included in the article's Creative Commons licence and your intended use is not permitted by statutory regulation or exceeds the permitted use, you will need to obtain permission directly from the copyright holder. To view a copy of this licence, visit http://creativecommons.org/licenses/by/4.0/ The Creative Commons Public Domain Dedication waiver (http://creativecommons.org/publicdomain/zero/1.0/) applies to the data made available in this article, unless otherwise stated in a credit line to the data. 


\section{Background}

Comprehensive cancer care requires a number of interventions, from specialized diagnostics to various treatments including: surgery, radiotherapy, and chemotherapy $[1,2]$. Low-cost and effective medicines to treat several cancers exist in generic form [3]. However, the prices of many cancer medicines (both generic and originators) make them unaffordable for governments and patients, and contribute to their in health facilities in many low- and middle-income countries (LMIC) [4]. Unavailable and unaffordable essential cancer medicines may lead to substandard and/or interrupted treatment regimens, worse health outcomes, and lower chances of survival [2]. Therefore, equitable access to affordable essential medicines is a crucial component of comprehensive cancer care [3, 5-7].

In absolute terms, cancer has become a leading cause of death and disability around the globe. Yet, many patients in LMIC remain untreated [2, 3, 8, 9], and access to cancer care, including medicines, is becoming a priority. Describing the current access to cancer medicines and understanding the barriers that hinder their accessibility [10] are key components to develop responsive national policies, and to measure their impact. In general, comparable information about access to cancer medicines is limited worldwide $[10,11]$. Direct assessment of the availability and affordability of essential cancer medicines has rarely been conducted in LMICs [11], except in Tanzania [12] and Pakistan [13]. Most studies have been limited to infectious diseases and medicines to treat non-communicable diseases (NCDs) other than cancer [14-17].

In Mexico, cancer accounts for nearly $13 \%$ of deaths [18-20]. Cancer care in Mexico is available in the public and private sectors. In the public sector, social health insurance institutions provide comprehensive health services (including cancer treatment) to employees in the formal sector. People who are ineligible for social health insurance can affiliate to the People's Health Insurance (Seguro Popular de Salud - SPS) - a federal government insurance scheme that reimburses health facilities (usually Ministry of Health (MoH) facilities) according to a catalog of services [21, 22]. This population can also receive coverage for high-cost services (e.g. all pediatric cancers and eight types of cancers in adults) through the Fund against Catastrophic Expenditures (FPGC) [2, 23]. SPS patients receive healthcare and medicines at the point of service with no additional cost. For those diseases not covered by SPS, patients might pay out-of-pocket for some services and medicines according to their level of income. The private sector consists of private pharmacies and health facilities where patients pay additional insurance contributions or out-of-pocket [21]. While several studies have investigated insurance coverage for breast, cervical and children cancer care in the public sector [23-25], there is scant research on the availability and affordability of cancer medicines.

The purpose of this study was to assess and compare the availability and affordability of essential cancer medicines in the public and private sectors in Mexico. We also compared consumer procurement and consumer prices in the two sectors against those in four other middle-income countries in the region (Brazil, Colombia, Chile and Peru).

\section{Methods}

The standardized World Health Organization/Health Action International (WHO/HAI) methodology [26] that measures medicine prices, availability and affordability was adapted to study essential medicines for cancer, collecting data from a sample of public hospitals and private pharmacies across the country.

\section{Sample}

We selected 49 cancer medicines (each strength and dose-form specific) from the national formulary. According to the national clinical guidelines, the SPS protocols and the National Institute of Cancerology's (INCAN) guidelines, these medicines are required for the treatment of breast cancer, colorectal cancer, leukemia and renal cancer. Of these, the SPS reimburses 40 medicines (for more information on the medicines of study see Additional file 1).

Data were collected in Mexican states where cancer care is provided. A total of 26 specialized and tertiary hospitals in the public sector were selected from eight of 32 states of the country, with differing levels of marginalization [27, 28], Organization for Economic Cooperation and Development (OECD) health well-being levels [29], and with at least one MoH hospital specialized in cancer care (Table 1). In this way, our sample captured the variability and characteristics of the health system. We surveyed all $\mathrm{MoH}$ hospitals providing cancer care in the selected states except in Chihuahua, Oaxaca and Veracruz. We did not survey five hospitals in these three states due to logistical issues and hospital's refusal to participate.

Cancer medicines are not always continuously stocked in private pharmacies. Instead, pharmacies that dispense these medicines usually do so from a fixed inventory list, with next-day delivery. We selected 1 to 3 pharmacies that market specialty medicines (e.g. cancer medicines) in each of the eight states, resulting in a total of 19 pharmacies.

\section{Data collection}

The survey was conducted from March to June 2017. From the public sector hospital pharmacies, we recorded whether the medicine was in stock at the time of the visit (yes/no), and the price paid by the hospital and by the patient (if applicable). We did not distinguish between 
Table 1 Characteristics of selected states and number of facilities surveyed

\begin{tabular}{lllll}
\hline State & Level of Marginalization & OECD $^{\text {Health well-being indicator }}$ & No. Public Hospitals surveyed & No. Private Pharmacies surveyed \\
\hline Campeche & High & Low & 1 & 1 \\
Oaxaca & High & Low & 2 & 2 \\
Veracruz & High & Low & 3 & 2 \\
Chihuahua & Medium & Low & 2 & 2 \\
Guanajuato & Medium & Medium & 3 & 3 \\
Yucatan & Medium & Medium & 2 & 3 \\
Jalisco & Low & High & 4 & 3 \\
Mexico City & Low & High & 4 & 3
\end{tabular}

${ }^{\mathrm{a} O E C D}$ Organization for Economic Co-operation and Development

originator brands or generics, because the Mexican public sector regularly procures generic versions of multisource medicines and only provides originator (patented) medicines when no generics are available.

In the private sector pharmacies, we recorded whether the medicine was included in the pharmacy's inventory and could be ordered for next-day delivery (yes/no), the price paid by patients of the lowest-priced generic available and the price of the patented medicines.

\section{Data analysis}

We conducted the data analysis using the WHO/HAI methodology workbook [26] as described in the following sections.

\section{Availability}

We assessed availability in each sector by calculating the percentage of facilities where each medicine was available, and the mean across a collection of medicines. In the public sector, we also compared availability per disease, since breast cancer and colorectal cancer are covered by SPS for adults and children, while leukemia and renal cancer are covered for children only.

\section{Affordability}

We assessed affordability from the patient's perspective when paying out-of-pocket. For each medicine, we compared the defined daily dose values [30] and the median unit price with the minimum daily wage in 2017 [26, 31]. Based on affordability assessments by Khatib et. $\mathrm{Al}$ [32] and Sarwar et al. [13], we considered a medicine as affordable if $20 \%$ or less of the daily wage was needed to pay for 1 day of medicine $[13,32]$. In public hospitals, affordability was only assessed in the three hospitals where patients pay out-of-pocket for cancer medicines. We were not able to include data from the other hospitals, as these reported that patients did not pay out-ofpocket for their medicines or only paid a co-payment (for all healthcare services) according to their level of income when they do not have SPS coverage.

\section{Prices and international price comparison}

The WHO/HAI methodology expresses prices as a ratio (Median Price Ratio (MPR)) to international reference prices, which are the median supplier prices reported by Management Sciences for Health (MSH) [33]. As MSH reported prices for a limited number of the study medicines, prices from publicly accessible websites of comparable countries in the region were also used as external benchmark, namely Brazil, Colombia, Chile (recently considered a high-income country) and Peru [3437]. To calculate MPRs, MSH international reference prices, the Pan-American Health Organization (PAHO) Strategic Fund procurement prices and 2017 median public sector procurement prices in the comparator countries were compared with Mexican public procurement prices. For patient prices, comparisons were made with median patient prices of patented and lowest priced generic medicines in the comparator countries.

\section{Results}

Availability and affordability of medicines in the public and private sectors

Table 2 shows the availability and affordability of cancer medicines in the public hospitals and private pharmacies we surveyed. In the public sector, the overall mean availability was $61.2 \%$, with $70.2 \%$ availability of the SPS medicines. Mean availability of medicines was: for breast cancer $81.8 \%$, for leukemia $69.2 \%$, for colorectal cancer $62.9 \%$, and renal cancer $57.3 \%$. Overall availability in the private sector was $67.4 \%$. Generic medicines (60.6\%) were more available than patented medicines (54.0\%). The availability of patented medicines was below $50 \%$ in the public and private sectors for most medicines except bevacizumab $400 \mathrm{mg}$, L-asparaginase, mercaptopurine, rituximab $100 \mathrm{mg}$ and $500 \mathrm{mg}$, and trastuzumab.

In the public sector, the median affordability $(n=49$ medicines) was 1.45 days' wages required to purchase 1 day's supply. Seven medicine products were considered affordable, that is, 1 day of medicine supply costs $20 \%$ or less of the daily wage: etoposide, fluorouracil, letrozole, methotrexate (2.5 mg tablet (tab), $500 \mathrm{mg}$ injectable (inj) 
Table 2 Availability and affordability of 49 selected cancer medicines in public hospitals and private pharmacies

\begin{tabular}{|c|c|c|c|c|c|}
\hline & & Availability & & Affordability $^{\text {a }}$ & \\
\hline No. & Medicine & Public Sector $(n=21)$ & Private Sector $(n=19)$ & Public Sector $(n=21)$ & Private Sector $^{b}(n=19)$ \\
\hline 1 & Anastrozole $1 \mathrm{mg}$ tab & $76.19 \%$ & $89.47 \%$ & 0.24 & 0.59 \\
\hline 2 & Bevacizumab 100 mg inj & $42.86 \%$ & $73.68 \%$ & 30.12 & 57.68 \\
\hline 3 & Bevacizumab 400 mg inj & $66.67 \%$ & $68.42 \%$ & 29.42 & 51.99 \\
\hline 4 & Capecitabine 500 mg tab & $76.19 \%$ & $78.95 \%$ & 1.88 & 5.50 \\
\hline 5 & Carboplatin 150 mg inj & $85.71 \%$ & $68.42 \%$ & 0.44 & 0.83 \\
\hline 6 & Cetuximab 5 mg/ml inj & $38.10 \%$ & $36.84 \%$ & 35.74 & 62.88 \\
\hline 7 & Cyclophosphamide 200 mg inj & $80.95 \%$ & $84.21 \%$ & 0.48 & 0.67 \\
\hline 8 & Cyclophosphamide 500 mg inj & $95.24 \%$ & $73.68 \%$ & 0.53 & 0.64 \\
\hline 9 & Cytarabine 500 mg inj & $95.24 \%$ & $84.21 \%$ & & \\
\hline 10 & Dasatinib 50 mg tab & $4.76 \%$ & $31.58 \%$ & 17.20 & 33.95 \\
\hline 11 & Daunorubicin 20 mg inj & $66.67 \%$ & $63.16 \%$ & & \\
\hline 12 & Docetaxel 20 mg/1 ml inj & $66.67 \%$ & $78.95 \%$ & 5.26 & 8.00 \\
\hline 13 & Docetaxel 80 mg/4 ml inj & $71.43 \%$ & $84.21 \%$ & 3.78 & 6.59 \\
\hline 14 & Doxorubicin $10 \mathrm{mg}$ inj & $85.71 \%$ & $73.68 \%$ & 0.61 & 1.09 \\
\hline 15 & Doxorubicin 50 mg inj & $85.71 \%$ & $84.21 \%$ & 0.45 & 0.57 \\
\hline 16 & Epirubicin $10 \mathrm{mg} / 5 \mathrm{ml}$ inj & $42.86 \%$ & $63.16 \%$ & & 3.00 \\
\hline 17 & Epirubicin 50 mg/25 ml inj & $61.90 \%$ & $84.21 \%$ & 0.57 & 1.86 \\
\hline 18 & Etoposide 20 mg/ml inj & $95.24 \%$ & $78.95 \%$ & 0.16 & 0.33 \\
\hline 19 & Everolimus 10 mg tab & $14.29 \%$ & $42.11 \%$ & 21.26 & 30.17 \\
\hline 20 & Everolimus 5 mg tab & $9.52 \%$ & $42.11 \%$ & & 30.17 \\
\hline 21 & Exemestane $25 \mathrm{mg}$ tab & $85.71 \%$ & $78.95 \%$ & 1.02 & 0.73 \\
\hline 22 & Fluorouracil 250 mg inj & $80.95 \%$ & $52.63 \%$ & 0.10 & 0.16 \\
\hline 23 & Folinic Acid $50 \mathrm{mg} / 4 \mathrm{ml}$ inj & $95.24 \%$ & $63.16 \%$ & & \\
\hline 24 & Folinic Acid 15 mg tab & $42.86 \%$ & $57.89 \%$ & & \\
\hline 25 & Gemcitabine $1 \mathrm{~g}$ inj & $76.19 \%$ & $78.95 \%$ & 1.09 & 4.86 \\
\hline 26 & Ifosfamide $1 \mathrm{~g}$ inj & $85.71 \%$ & $73.68 \%$ & 3.15 & 5.50 \\
\hline 27 & Imatinib 100 mg tab & $33.33 \%$ & $63.16 \%$ & 3.58 & 17.59 \\
\hline 28 & Imatinib 400 mg tab & $38.10 \%$ & $47.37 \%$ & 3.43 & 18.63 \\
\hline 29 & Irinotecan 20 mg/ml inj & $76.19 \%$ & $68.42 \%$ & 3.18 & 7.25 \\
\hline 30 & L-Asparaginase $10,000 \mathrm{IU}$ inj & $76.19 \%$ & $84.21 \%$ & 13,15 & 17.03 \\
\hline 31 & Letrozole $2.5 \mathrm{mg}$ tab & $66.67 \%$ & $84.21 \%$ & 0.20 & 0.44 \\
\hline 32 & Mercaptopurine 50 mg tab & $52.38 \%$ & $84.21 \%$ & 1.45 & 2.38 \\
\hline 33 & Methotrexate $2.5 \mathrm{mg}$ tab & $71.43 \%$ & $84.21 \%$ & 0.02 & 0.07 \\
\hline 34 & Methotrexate 500 mg inj & $80.95 \%$ & $78.95 \%$ & 0.02 & 0.02 \\
\hline 35 & Methotrexate 50 mg inj & $95.24 \%$ & $68.42 \%$ & 0.06 & 0.11 \\
\hline 36 & Nilotinib 200 mg tab & $23.81 \%$ & $36.84 \%$ & & 21.72 \\
\hline 37 & Oxaliplatin 100 mg/20 ml inj & $61.90 \%$ & $84.21 \%$ & 0.89 & 2.36 \\
\hline 38 & Oxaliplatin 50 mg/10 ml inj & $57.14 \%$ & $73.68 \%$ & 1.25 & 2.40 \\
\hline 39 & Paclitaxel 6 mg/ml inj & $80.95 \%$ & $78.95 \%$ & 0.45 & 1.63 \\
\hline 40 & Panitimumab 20 mg/ml inj & $28.57 \%$ & $42.11 \%$ & 31.72 & 58.93 \\
\hline 41 & Pazopanib 200 mg tab & $9.52 \%$ & $26.32 \%$ & & 14.89 \\
\hline 42 & Pazopanib 400 mg tab & $4.76 \%$ & $52.63 \%$ & 8.49 & 14.89 \\
\hline 43 & Rituximab 100 mg/10 ml inj & $61.90 \%$ & $68.42 \%$ & 6.65 & 30.97 \\
\hline
\end{tabular}


Table 2 Availability and affordability of 49 selected cancer medicines in public hospitals and private pharmacies (Continued)

\begin{tabular}{|c|c|c|c|c|c|}
\hline & & Availability & & Affordability $^{a}$ & \\
\hline 44 & Rituximab $500 \mathrm{mg} / 50 \mathrm{ml}$ inj & $71.43 \%$ & $68.42 \%$ & 4.65 & 30.96 \\
\hline 45 & Sorafenib $200 \mathrm{mg}$ tab & $19.05 \%$ & $57.89 \%$ & 19.59 & 31.13 \\
\hline 46 & Sunitinib $12.5 \mathrm{mg}$ tab & $14.29 \%$ & $47.37 \%$ & 11.89 & 25.10 \\
\hline 47 & Tamoxifen 20 mg tab & $90.48 \%$ & $78.95 \%$ & 0.02 & 0.06 \\
\hline 48 & Trastuzumab 440 mg inj & $71.40 \%$ & $57.89 \%$ & 13.77 & 23.63 \\
\hline \multirow[t]{7}{*}{49} & Vincristine 1 mg inj & $85.71 \%$ & $78.95 \%$ & 0.35 & 0.45 \\
\hline & Mean availability/Median affordability & $61.20 \%$ & $67.45 \%$ & 1.45 & 5.50 \\
\hline & Mean availability/Median affordability: & & & & \\
\hline & Breast cancer medicines & $74.8 \%$ & $78.1 \%$ & 0.57 & 1.36 \\
\hline & Leukemia medicines & $59.3 \%$ & $66.4 \%$ & 3.50 & 17.72 \\
\hline & Colorectal cancer medicines & $55.6 \%$ & $58.3 \%$ & 2.53 & 6.37 \\
\hline & Renal cancer medicines & $52.0 \%$ & $61.9 \%$ & 1.09 & 17.72 \\
\hline
\end{tabular}

tab tablet, inj injectable, $\mathrm{mg}$ milligrams, $\mathrm{m} /$ milliliters, $I U$ international unit, $n$ number of facilities surveyed and included in the analysis

${ }^{a}$ Affordability is expressed as number of days needed to purchase 1 day of treatment based in minimum daily wage

${ }^{b}$ Affordability in the private sector: we present only the affordability of the lowest priced generic medicines. For medicines with no generic alternatives, we present the affordability of the patented/originator medicine

and $50 \mathrm{mg}$ inj) and tamoxifen. In the private sector, five medicine products were considered affordable: fluorouracil, methotrexate $500 \mathrm{mg}$ inj and $50 \mathrm{mg}$ inj, tamoxifen, and methotrexate $2.5 \mathrm{mg}$ tab. The median price of overall medicines in the private sector was 5.50 days' wages needed to buy 1 day of one medicine's supply. The median affordability of patented medicines was 30.17 days' wages needed to buy 1 day of one medicine's supply. For the generic medicines, it was 0.78 days' wages.

\section{Procurement and patient prices}

Table 3 shows median public sector procurement prices and median patient prices in the private sector, both in local currency (Mexican peso (Mex\$)) and as ratios to median prices in the four comparator countries and international reference prices. In the public sector, the overall median procurement price in Mexico was 0.59 times ( $41 \%$ below) the median comparator country price and 0.80 times (20\% below) the MSH international reference prices. However, the prices of a few individual medicines were over twice the median comparator country price, e.g. MPR of anastrozole (2.12x), docetaxel 80 $\mathrm{mg}(5.56 \mathrm{x})$ and $20 \mathrm{mg}$ inj $(3.40 \mathrm{x})$. The prices of docetaxel $20 \mathrm{mg} / \mathrm{ml}(12.42 \mathrm{x})$ and $80 \mathrm{mg} / \mathrm{ml}(12.08 \mathrm{x})$, folinic acid $50 \mathrm{mg} / \mathrm{ml}(3.88 \mathrm{x})$ and irinotecan (6.16x) were over three times the MSH international reference prices. For patient prices in the private sector, overall medicines had median MPRs of 0.65 (35\% below the reference prices). Cancer medicines ranged from an MPR of 0.13 for oxaliplatin $50 \mathrm{mg}$ inj to 2.48 for docetaxel $80 \mathrm{mg}$ inj. Most medicine prices were 2 to 6 times higher in the other Latin American (LATAM) countries compared to Mexico. On the other hand, six medicines were cheaper in Peru. Only the price of docetaxel was consistently higher in Mexico (Fig. 1).

\section{Discussion}

In Mexico, the overall availability of cancer essential medicines in the public sector was slightly lower than in the private sector. In general, prices in Mexico were lower than international reference prices and lower than other LATAM countries. Only few medicines were considered affordable in both the public and private sectors; affordability of medicines in the public sector $(14 \%$ of medicines) was slightly better than in the private sector (10\% of medicines).

\section{Availability of cancer medicines}

The average availability of cancer medicines was lower in the public sector $(61.2 \%)$ than in the private sector (67.45\%), with high variability across individual medicines. The availability of SPS medicines was slightly higher (70.2\%), especially for those for breast cancer and leukemia. Greater availability reflects an increased government investment in these two types of cancer treatments. Access to colorectal cancer medicines was lower than breast cancer and leukemia medicines; barriers to access essential medicines for colorectal cancer have been reported [22], despite the fact that colorectal cancer is covered by SPS. Renal cancer medicines for adult patients had the lowest availability of all, likely because they are not covered by SPS and therefore deprioritized [38, 39].

Overall, the availability of cancer medicines falls below the World Health Organization's (WHO) target of 80\% for essential medicines to treat major NCDs (which includes cancer) [40-42]. Thus, mechanisms to improve the availability of cancer medicines in Mexico are warranted. 
Table 3 Median public sector procurement prices and median patient prices, in local currency and as price ratios to median prices in the four-comparator countries

\begin{tabular}{|c|c|c|c|c|c|c|}
\hline \multirow[b]{2}{*}{ No. } & \multirow[b]{2}{*}{ Medicine Name } & \multicolumn{3}{|c|}{ Public Sector Procurement Price } & \multicolumn{2}{|c|}{ Private Sector Patient Price ${ }^{\mathbf{a}}$} \\
\hline & & Median Price (Mex\$) & MPR (LATAMC) & MPR (MSH) & Median Price (Mex\$) & MPR (LATAMC) \\
\hline 1 & Anastrozole $1 \mathrm{mg}$ tab & 24.29 & 2.12 & 2.35 & 47.36 & 1.27 \\
\hline 2 & Bevacizumab 100 mg inj & 53.58 & 0.58 & & 102.59 & 0.82 \\
\hline 3 & Bevacizumab 400 mg inj & 48.67 & 0.66 & & 92.48 & 0.84 \\
\hline 4 & Capecitabine 500 mg tab & 22.07 & 0.59 & 0.67 & 73.33 & 0.89 \\
\hline 5 & Carboplatin $150 \mathrm{mg}$ inj & 1.27 & 0.31 & 0.65 & 2.67 & 0.21 \\
\hline 6 & Cetuximab 5 mg/ml inj & 40.81 & 0.61 & & 77.43 & 1.01 \\
\hline 7 & Cyclophosphamide 200 mg inj & 0.15 & 0.41 & 0.36 & 0.21 & 0.35 \\
\hline 8 & Cyclophosphamide 500 mg inj & 0.14 & 0.37 & 0.45 & 0.20 & 0.42 \\
\hline 9 & Cytarabine 500 mg inj & 0.30 & 1.08 & 1.66 & 0.60 & 0.58 \\
\hline 10 & Dasatinib 50 mg tab & 573.78 & 0.57 & & 1132.27 & 1.46 \\
\hline 11 & Daunorubicin 20 mg inj & 5.90 & 0.25 & 0.31 & 12.99 & 0.31 \\
\hline 12 & Docetaxel 20 mg/1 ml inj & 62.93 & 3.40 & 12.42 & 99.53 & 0.54 \\
\hline 13 & Docetaxel 80 mg/4 ml inj & 51.83 & 5.56 & 12.08 & 82.00 & 2.48 \\
\hline 14 & Doxorubicin 10 mg inj & 7.45 & 1.23 & 1.79 & 17.53 & 0.42 \\
\hline 15 & Doxorubicin 50 mg inj & 3.92 & 0.86 & 1.38 & 9.20 & 0.49 \\
\hline 16 & Epirubicin 10 mg/5 ml inj & 12.84 & 0.36 & 1.20 & 34.35 & 0.59 \\
\hline 17 & Epirubicin 50 mg/25 ml inj & 6.20 & 0.41 & 0.73 & 21.28 & 0.38 \\
\hline 18 & Etoposide 20 mg/ml inj & 0.49 & 0.64 & 1.30 & 1.06 & 2.01 \\
\hline 19 & Everolimus 10 mg tab & 1702.00 & 0.83 & & 2414.97 & 0.65 \\
\hline 20 & Everolimus 5 mg tab & 425.50 & 0.44 & & 1207.48 & 0.65 \\
\hline 21 & Exemestane $25 \mathrm{mg}$ tab & 69.18 & 1.08 & 1.69 & 58.50 & 0.66 \\
\hline 22 & Fluorouracil $250 \mathrm{mg}$ inj & 0.08 & 0.49 & 0.38 & 0.13 & 0.63 \\
\hline 23 & Folinic Acid 50 mg/4 ml inj & 3.56 & 0.76 & 3.88 & 4.60 & 1.14 \\
\hline 24 & Folinic Acid 15 mg tab & 15.84 & 0.71 & 0.62 & 23.33 & 0.80 \\
\hline 25 & Gemcitabine $1 \mathrm{~g}$ inj & 0.44 & 0.32 & 0.89 & 1.95 & 0.37 \\
\hline 26 & Ifosfamide $1 \mathrm{~g}$ inj & 0.27 & 0.75 & 1.30 & 0.63 & 0.83 \\
\hline 27 & Imatinib 100 mg tab & 57.32 & 0.54 & 4.22 & 281.58 & 0.52 \\
\hline 28 & Imatinib 400 mg tab & 219.48 & 0.77 & 0.44 & 1192.74 & 0.66 \\
\hline 29 & Irinotecan 20 mg/ml inj & 6.97 & 1.20 & 6.16 & 19.34 & 0.35 \\
\hline 30 & L-Asparaginase 10,000 IU inj & 0.11 & 0.49 & 1.06 & 0.14 & 0.92 \\
\hline 31 & Letrozole $2.5 \mathrm{mg}$ tab & 2.62 & 0.04 & 0.28 & 35.00 & 1.03 \\
\hline 32 & Mercaptopurine 50 mg tab & 33.24 & 0.59 & 0.76 & 54.48 & 1.25 \\
\hline 33 & Methotrexate $2.5 \mathrm{mg}$ tab & 1.20 & 0.36 & 0.39 & 5.81 & 1.73 \\
\hline 34 & Methotrexate 500 mg inj & 0.45 & 1.13 & 1.35 & 0.79 & 0.61 \\
\hline 35 & Methotrexate 50 mg inj & 1.22 & 0.59 & 0.59 & 3.44 & 1.05 \\
\hline 36 & Nilotinib 200 mg tab & 279.07 & 0.56 & 11.92 & 579.59 & 0.84 \\
\hline 37 & Oxaliplatin 100 mg/20 ml inj & 6.36 & 0.78 & 0.43 & 17.15 & 0.18 \\
\hline 38 & Oxaliplatin 50 mg/10 ml inj & 8.52 & 1.11 & 0.75 & 17.45 & 0.13 \\
\hline 39 & Paclitaxel 6 mg/ml inj & 2.78 & 0.76 & & 8.72 & 0.58 \\
\hline 40 & Panitimumab 20 mg/ml inj & 76.99 & 0.84 & & 157.23 & 1.18 \\
\hline 41 & Pazopanib 200 mg tab & 170.44 & 0.56 & & 297.90 & 0.59 \\
\hline 42 & Pazopanib 400 mg tab & 339.86 & 0.57 & & 595.85 & 0.45 \\
\hline
\end{tabular}


Table 3 Median public sector procurement prices and median patient prices, in local currency and as price ratios to median prices in the four-comparator countries (Continued)

\begin{tabular}{|c|c|c|c|c|c|c|}
\hline \multirow[b]{2}{*}{ No. } & \multirow[b]{2}{*}{ Medicine Name } & \multicolumn{3}{|c|}{ Public Sector Procurement Price } & \multicolumn{2}{|c|}{ Private Sector Patient Price $^{\mathbf{a}}$} \\
\hline & & Median Price (Mex\$) & MPR (LATAMC) & MPR (MSH) & Median Price (Mex\$) & MPR (LATAMC) \\
\hline 43 & Rituximab $100 \mathrm{mg} / 10 \mathrm{ml}$ inj & 13.09 & 0.45 & 0.49 & 77.46 & 0.85 \\
\hline 44 & Rituximab $500 \mathrm{mg} / 50 \mathrm{ml}$ inj & 10.82 & 0.21 & 0.31 & 77.44 & 1.26 \\
\hline 45 & Sorafenib 200 mg tab & 404.04 & 0.73 & & 622.82 & 0.67 \\
\hline 46 & Sunitinib $12.5 \mathrm{mg}$ tab & 326.01 & 0.43 & & 717.58 & 0.53 \\
\hline 47 & Tamoxifen 20 mg tab & 1.46 & 0.68 & 0.66 & 4.90 & 0.41 \\
\hline 48 & Trastuzumab 440 mg inj & 49.29 & 0.68 & & 94.56 & 0.97 \\
\hline \multirow[t]{2}{*}{49} & Vincristine $1 \mathrm{mg}$ inj & 53.66 & 0.36 & 0.84 & 101.00 & 0.53 \\
\hline & Median & 12.84 & 0.59 & 0.80 & 41.18 & 0.65 \\
\hline
\end{tabular}

$O B$ originator brand, LPG lowest price generic, tab tablet, inj injectable, $m g$ milligrams, $\mathrm{ml}$ milliliters, IU international unit, $n$ number of facilities surveyed and included in the analysis, LATAMc Latin American countries, MPR median price ratio, Mex\$ mexican peso, MSH management sciences for health

${ }^{a}$ Median prices and MPR in the private sector: we present only the median prices and the MPR of the lowest priced generic medicines. For medicines with no generic alternatives, we present the median prices and the MPR of the patented/originator medicine

Low availability in the private sector could be explained by the fact that specialized medicines are marketed in selected pharmacy chains only. Therefore, patients have a limited choice of pharmacies, restricted to some states and mostly in urban areas.

The availability of cancer medicines in Mexico's public sector is higher than other LMIC countries from which data were available. For example, studies in Tanzania and Pakistan $[12,13]$ reported $50 \%$ availability of cancer medicines in the public sector. In Pakistan, the availability of cancer medicines in the private sector was higher than in the public sector, which is a common trend in LMIC [13]. However, private pharmacies in Pakistan focus more on stocking originator brand cancer medicines, while in Mexico private pharmacies have a better availability of generic cancer medicines [13].

\section{Affordability of cancer medicines}

Most cancer medicines are unaffordable for patients, in the private and in three public hospitals where patients paid for cancer medicines. Based on our own definition, only 7 out of 49 cancer medicines were affordable [13, 32]. In addition, most cancer treatment regimens require more than one medicine, making the treatment as a whole even less affordable, often leading to catastrophic expenditures and poverty $[6,43,44]$. The studies from Tanzania and Pakistan also reported that cancer medicines required more than one working day to pay for 1 day of treatment, therefore considered unaffordable to most patients [12, 13]. These results, including Mexico, confirm the LMIC's general picture of unaffordability of essential cancer medicines. Therefore, more aggressive pricing policies are needed to disrupt this ongoing problem.

We also found that 18 out of 21 of the public hospitals we surveyed reported no additional charges for patients without SPS coverage, as a mechanism to guarantee access to treatment without incurring in health expenditure. For those hospitals that do charge uninsured patients for treatment, these patients must make out-ofpocket payments for (mostly) unaffordable medicines and/or turn to charity organizations $[23,45]$.

\section{Procurement prices and international price comparison}

We found that, in general, prices of cancer medicines in the public sector in Mexico were lower than other LATAM countries and international reference prices. The Mexican government has contained procurement prices better in the public sector than other countries in the region, through pooled procurement, price negotiations and using reference pricing for SPS medicines [4649]. For SPS medicines, most public procurement prices were under the SPS reference prices [47, 50], and overall about 20\% lower than (MSH) international reference prices. Still, additional efforts are needed to further reduce and monitor prices; in particular for those that are more than twice the reference prices (e.g. docetaxel).

Overall, medicine prices in Mexico's private sector were lower than retail prices in the regional countries. Yet, current prices, especially for patented medicines, remain unaffordable, warranting the development of comprehensive price regulations schemes, which has not been properly introduced in the country yet $[46,51]$. High prices of patented cancer medicines seem common in the region, as other LATAM countries, such as Argentina, Chile, Uruguay, Paraguay and Brazil have reported unaffordable prices as well [52]. Such high prices in the private sector usually lead to catastrophic expenditure, in particular for low-income patients who were unable to get their medicines in the public sector [6]. Besides wider national health insurance coverage for public sector medicines, additional pricing policies are 


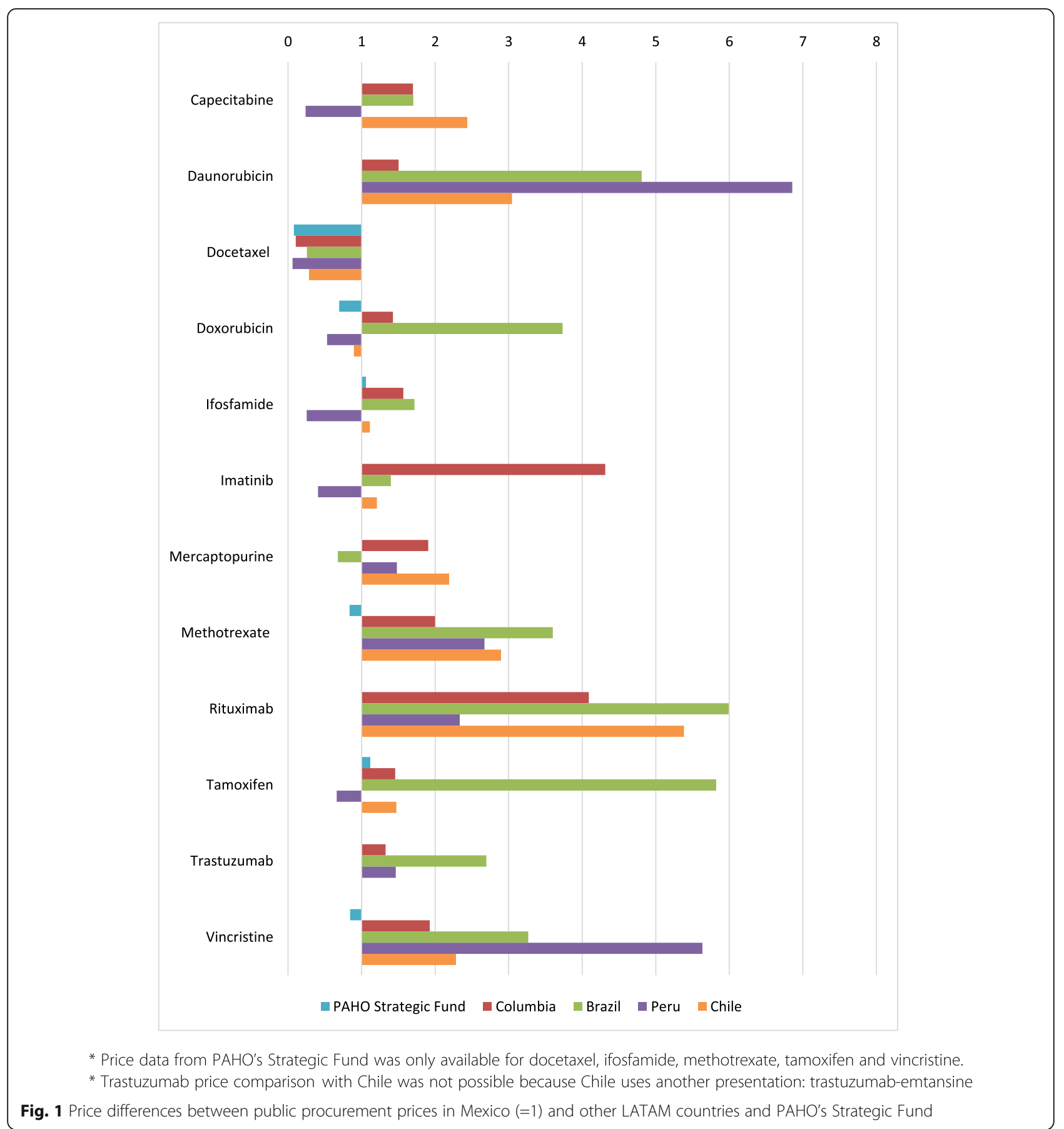

necessary to improve access to more affordable cancer medicines in the private sector.

\section{Strengths and limitations}

To our knowledge, this is the first study on the availability, prices, and affordability of cancer medicines using an adapted form of the WHO/HAI methodology. This study collected data from a representative sample of public hospitals and private pharmacies in eight states. Future research should also consider assessing the availability, affordability, and prices of cancer medicines in other insurance schemes (social health insurance institutions) and other geographic regions of Mexico.

This study has some limitations. At the time of data collection, some medicines were reported as "just became out-of-stock". Thus, our availability data may underestimate the actual availability of cancer medicines on a regular basis [26]. At one surveyed hospital, some 
medicine prices were restricted, as this information pertained to the state's $\mathrm{MoH}$ database. In addition, our calculations of patient affordability account for single medicine for 1 day of treatment, which may underestimate the affordability of the treatment as a whole. Furthermore, our affordability assessment in the public sector is limited to the only 3 hospitals that reported patient prices for cancer medicines, which may understate our results on medicine's affordability in the public sector. However, the current results show that medicines are still unaffordable to patients that receive care at those institutions and pay out of pocket for medicines without coverage.

We only surveyed pharmacies in the private sector because we did not obtain approval from private hospitals to conduct our research. Private hospitals providing cancer care provide chemotherapy at their facilities and care for approximately 19\% of cancer cases [53]. Hence, our results do not fully represent the availability, prices, and affordability of cancer medicines in the private sector as a whole. However, the private sector hospitals and clinics represent approximately $2 \%$ [54] of the pharmaceutical market. Thus, omitting these data is not likely to have resulted in significant bias in our observations. Additional research is necessary to describe the availability and affordability of cancer medicines in this private subsector.

\section{Practical implications}

Medicines in the public sector covered by SPS were the most available, especially for breast cancer and leukemia. These results reflect the additional investment by the government to improve health care access to priority diseases. We recommend periodically revising and updating the SPS's protocols for "resource appropriate strategies" [2] that guarantee the best level of care with the most efficacious and cost-effective medicines, including innovative medicines. We also recommend the expansion of SPS coverage to improve access to treatment to all types of cancer.

Overall, the Mexican government has kept prices of cancer medicines in the public sector below prices from other LATAM countries. Yet, most medicines remain unaffordable for patients - particularly for innovative medicines under patent. A comprehensive assessment of the government's budget allocations and the complete calculation of costs of cancer care (i.e. pharmaceutical and non-pharmaceutical) are required.

The high prices and low affordability of cancer medicines in the private sector reflect a lack of pricing policies and pharmaceutical market regulation. Price monitoring, prices transparency for single-source products, and compulsory licensing when all other measured fail to yield affordable medicines, should be implemented to increase affordability for payers (patients and the health system). Mexico should also consider the full range of pricing policies [55] for medicines in the public and private sectors to assure the provision of affordable medicines for all patients.

Further research is needed to assess the affordability of medicines and comprehensive cancer treatments, both from the patient's and the health system's perspective. Continuous monitoring of prices and availability of cancer medicines is necessary to monitor their impact on health expenditure and access to cancer care.

\section{Conclusions}

The availability of cancer medicines in public hospitals and private pharmacies in Mexico need to improve in order to reach WHO's target of $80 \%$ availability. The SPS should be used as a public mechanism to ensure appropriate and timely access to cancer medicines. Although prices in the public sector were lower than in other countries of the region, most cancer medicines continue to be unaffordable to patients in Mexico. Comprehensive pricing policies are needed to improve the affordability of cancer medicines in the public and private sectors.

\section{Supplementary information}

Supplementary information accompanies this paper at https://doi.org/10. 1186/s12913-020-05167-9.

Additional file 1. Medicines of study and their characteristics. Characteristics of selected medicines of study following inclusion criteria.

\section{Abbreviations}

CG: Clinical Guidelines; FPGC: Fund against catastrophic expenditures; INCAN: National Institute of Cancerology (Instituto Nacional de

Cancerología); inj: injectable; INSP: National Institute of Public Health (Instituto Nacional de Salud Pública); IU: International unit; LATAM: Latin America; LMIC: Low- and middle-income countries; LPG: Lowest Price Generic; Mex\$: Mexican Peso; mg: milligram; MIC: Middle-income country; ml: milliliter; $\mathrm{MoH}$ : Ministry of Health; MPR: Median price ratio; MSH: Management sciences for health; NCD: Non-communicable diseases; NCG: National clinical guidelines; OB: Originator brand; OECD: Organization for economic co-operation and development; PAHO: Pan-American Health Organization; SPS: People's Health Insurance (Seguro Popular de Salud); tab: tablet; WHO: World Health Organization

\section{Acknowledgements}

We thank Dr. Alejandro Mohar and the National Institute of Cancerology (INCan) in Mexico for their continuous interest, support, and feedback during the planning and execution of this study. In addition, we thank the Hospital General de México "Dr. Eduardo Liceaga" for its support during data collection and the execution of the study. We thank all institutions and hospitals that contributed and provided access to their facilities during data collection. We also thank Katrina Perehudoff for her input and support during the writing and proofreading process of the manuscript. This work was supported by CONACYT (National Council of Science and Technology Mexico) (DMH scholarship 217161).

The abstract of this study was submitted to the World Cancer Congress 2018 and published accordingly in the Journal of Global Oncology (DOI: https:// doi.org/10.1200/jgo.18.88900). 


\section{Availability of data and material}

The datasets used and/or analyzed during the current study are available from the corresponding author on reasonable request.

\section{Authors' contributions}

$\mathrm{DMH}$ carried out the planning and design of the study, the data collection, data analysis and discussion and interpretation of the results. She carried out the writing of the manuscript. ME and $\mathrm{HVH}$ contributed to the planning and design of the methodology and the study, carried out revisions of the data analysis, and revisions and editing of the manuscript. AD, SBA and RSS contributed to the planning of the study, carried out revisions and editing of the manuscript. JPVD and SAR carried out revisions and editing of the manuscript. All authors read and approved the final manuscript.

\section{Funding}

This work was part of a Ph.D. research degree. The Ph.D. candidate received a scholarship from CONACYT (National Council of Science and Technology Mexico) (DMH scholarship 217161) to finance her degree, which includes the present study.

\section{Ethics approval and consent to participate}

The Ethics and Research Committee of the National Institute of Public Health in Mexico (INSP) (called CINBIOETICA) approved this study prior to data collection (reference number $\mathrm{Cl}$-1406). No consent to participate was necessary for this study since no patients or subjects participated in it. All participating institutions were contacted by $\mathrm{DMH}$ beforehand to request access to the facilities to conduct the survey. Access was granted via email to the research team before data collection.

\section{Consent for publication}

Not applicable.

\section{Competing interests}

The authors declare that they have no competing interests.

\section{Author details}

${ }^{1}$ Department of Community and Occupational Medicine, University Medical Center Groningen, University of Groningen, Hanzeplein 1, $9713 \mathrm{GZ}$ Groningen, The Netherlands. ${ }^{2}$ Health Action International (HAl), Overtoom 60, 1054 HK Amsterdam, the Netherlands. ${ }^{3}$ National Institute of Public Health (INSP), Avenida Universidad 655, Santa María Ahuacatitlán, 62100 Cuernavaca, Morelos, Mexico. ${ }^{4}$ Boston University School of Public Health, 715 Albany St, Boston, Massachusetts 02118, EE. UU, USA.

\section{Received: 28 November 2019 Accepted: 27 March 2020}

\section{Published online: 14 May 2020}

\section{References}

1. Olver I. Cancer control-a global perspective. Eur J Cancer Care (Engl). 2017; 26(1). https://doi.org/10.1111/ecc.12654.

2. Knaul FM, Frenk J, Shulman L. For the Global Task Force on Expanded Access to Cancer Care and Control in Developing Countries. Closing the Cancer Divide: A Blueprint to Expand Access in Low and Middle Income Countries. Boston: Harvard Global Equity Initiative; 2011.

3. de Lima LG, De Souza JA, Barrios C. Access to cancer medications in lowand middle-income countries. Nat Rev Clin Oncol. 2013;10:314-22.

4. Siddiqui M, Vincent RS. The high cost of Cancer drugs and what we can do about it. Mayo Clin Proc. 2012;87:935-43.

5. Mattke S, Haims M, Ayivi-Guedehossour N, Gillen E, Hunter L, Klautzer L, et al. Improving access to medicines for non-communicable diseases in the developing world. 2011.

6. Hogerzeil HV, Liberman J, Wirtz VJ, Kishore SP, Selvaraj S, Kiddell-Monroe R, et al. Promotion of access to essential medicines for non-communicable diseases: practical implications of the un political declaration. Lancet. 2013; 381:680-9.

7. Ruff P, Al-Sukhun S, Blanchard C, Shulman LN. Access to Cancer therapeutics in low- and middle-income countries. Am Soc Clin Oncol Educ Book. 2016;35:58-65. https://doi.org/10.14694/EDBK_155975.

8. World Health Organization. Cancer. 2018. https://www.who.int/news-room/ fact-sheets/detail/cancer. Accessed 15 Mar 2019.
9. Stewart BW, Wild CP. World Cancer Report 2014. Lyon: International Agency for Research on Cancer, World Health Organization; 2014.

10. Hanna TP, Kangolle AC. Cancer control in developing countries: using health data and health services research to measure and improve access, quality and efficiency. BMC Int Heal Hum Rights. 2010;10:24.

11. Bazargani YT, de Boer A, Schellens JHM, Leufkens HGM, Mantel-Teeuwisse AK. Selection of oncology medicines in low-and middle-income countries. Ann Oncol. 2014;25:270-6.

12. Yohana E, Kamuhabwa A, Mujinja P. Availability and affordability of anticancer medicines at the ocean road Cancer Institute in Dar es salaam, Tanzania. East Africa J Public Heal. 2011;8:52-7.

13. Sarwar MR, Iftikhar S, Saqib A. Availability of anticancer medicines in public and private sectors, and their affordability by low, middle and highincome class patients in Pakistan. BMC Cancer. 2018;18:14.

14. van Mourik MSM, Cameron A, Ewen M, Laing RO. Availability, price and affordability of cardiovascular medicines: a comparison across 36 countries using WHO/HAl data. BMC Cardiovasc Disord. 2010;10:25.

15. Cameron A, Ewen M, Ross-Degnan D, Ball D, Laing R. Medicine prices, availability, and affordability in 36 developing and middle-income countries: a secondary analysis. Lancet. 2009;373(9659):240-9. https://doi.org/10.1016/ S0140-6736(08)61762-6.

16. Mendis S, Fukino K, Cameron A, Laing R, Filipe A, Khatib O, et al. The availability and affordability of selected essential medicines for chronic diseases in six low- and middle-income countries. Bull World Health Organ. 2007:85(4):279-88

17. Ewen M, Zweekhorst M, Regeer B, Laing R. Baseline assessment of WHO's target for both availability and affordability of essential medicines to treat non-communicable diseases. PLoS One. 2017;12(2):e0171284. https://doi. org/10.1371/journal.pone.0171284.

18. World Health Organization. Noncommunicable Diseases Country Profiles 2014. Geneva: World Health Organization; 2014.

19. Reynoso-Noverón N, Meneses-García A, Erazo-Valle A, Escudero-de los Ríos P, Antonio Kuri-Morales P, Mohar-Betancourt A, et al. Challenges in the development and implementation of the National Comprehensive Cancer Control Program in Mexico. Salud Publica Mex. 2016;58:325-33.

20. Mohar-Betancourt A, Reynoso-Noverón N, Armas-Texta D, Gutiérrez-Delgado C, Torres-Domínguez JA. Cancer trends in Mexico: essential data for the creation and follow-up of public policies. J Glob Oncol. 2017:3:740-8.

21. Gómez Dantés O, Sesma S, Becerril V, Knaul FM, Arreola H, Frenk J. Sistema de salud de México [the health system of Mexico]. Salud Publica Mex. 2011; 53:S220-32.

22. Verastegui $\mathrm{E}$, Mohar A. Colorectal cancer in Mexico: should a middle income country invest in screening or in treatment? Eur J Health Econ. 2010;10:S107-14.

23. Pérez-Cuevas R, Doubova SV, Zapata-Tarres M, Flores-Hernández S, Frazier L, Rodríguez-Galindo C, et al. Scaling up cancer care for children without medical insurance in developing countries: the case of Mexico. Pediatr Blood Cancer. 2013:60:196-203.

24. Cervantes CAD, Botero MA. Average years of life lost due to breast and cervical cancer and the association with the marginalization index in Mexico in 2000 and 2010. Cad Saude Publica. 2014;30(5):1093-102.

25. González-Robledo MC, Wong R, Ornelas HA, Knaul FM. Costs of breast cancer care in Mexico: analysis of two insurance coverage scenarios. Ecancermedicalscience. 2015;28;9:587. https://doi.org/10.3332/ecancer.2015. 587.

26. World Health Organization, Health Action International. Measuring medicine prices, availability, affordability and price components. 2nd ed. Switzerland: World Health Organization; 2008. p. 293.

27. Gómez-Dantés H, Fullman N, Lamadrid-Figueroa H, Cahuana-Hurtado L, Darney B, Avila-Burgos $L$, et al. Dissonant health transition in the states of Mexico, 1990-2013: a systematic analysis for the Global Burden of Disease Study 2013. Lancet. 2016;388(10058):2386-402. https://doi.org/10.1016/ S0140-6736(16)31773-1.

28. Consejo Nacional de Población. Índice de marginación por entidad federativa y municipio 2015. https://www.gob.mx/conapo/documentos/ indice-de-marginacion-por-entidad-federativa-y-municipio-2015. Accessed 15 Jan 2017.

29. OECD. Measuring well-being in Mexican states. Paris: OECD Publishing; 2015. https://doi.org/10.1787/9789264246072-en.

30. Wissenschaftliches Insitut der AOK. Deutschen Institut für Medizinsche Dokumentation und Information. Anatomisch-therapeutisch-chemische Klassifikation mit Tagesdosen. 2017. 
31. Secretaría de Hacienda y Crédito Público. Salarios Mínimos 2017. http:// www.sat.gob.mx/informacion_fiscal/tablas_indicadores/paginas/salarios_ minimos.aspx. Accessed 20 Feb 2017.

32. Khatib R, McKee M, Shannon H, Chow C, Rangarajan S, Teo K, et al. Availability and affordability of cardiovascular disease medicines and their effect on use in high-income, middle-income, and low-income countries: an analysis of the PURE study data. Lancet. 2016;387:61-9.

33. Management Sciences for Health. International Medical Products Price Guide. http://mshpriceguide.org/en/home/. Accessed 9 August 2017.

34. Secretaria Executiva. Banco de precos de saúde. http://bps.saude.gov.br/ login.jsf. Accessed 25 Sept 2017.

35. MINSALUD. Termómetro de precios de medicamentos. https://www. minsalud.gov.co/salud/MT/Paginas/termometro-de-precios.aspx. Accessed 25 Sept 2017.

36. Ministerio de Salud. Observatorio Peruano de Productos Farmacéuticos. Sistema Nacional de Información de Precios http://observatorio.digemid. minsa.gob.pe/. Accessed 25 Sept 2017.

37. ChileCompra. Mercado Público - La plataforma de compras públicas y oportunidades de negocio del Estado de Chile. https://www. mercadopublico.cl/Home/BusquedaLicitacion. Accessed 25 Sept 2017.

38. O'Shea Cuevas GJ. Seguro popular: hacia la cobertura del paciente oncológico [Seguro popular: towards cover for the oncology patient]. Gac Mex Oncol. 2015;14(3):133-4.

39. Secretaría de Salud. Comisión Nacional de Protección Social en Salud. Anexo | 2017. http://www.seguro-popular.gob.mx/images/Contenidos/ gestion/ANEXO_I_2017.pdf. Accessed 7 Jan 2017.

40. World Health Assembly. Follow-up to the Political Declaration of the Highlevel Meeting of the General Assembly on the Prevention and Control of Non-communicable Diseases. Sixty-Sixth World Health Assemby. 2013. http://apps.who.int/gb/ebwha/pdf_files/WHA66/A66_R10-en.pdf?ua=1. Accessed 17 Aril 2018.

41. Cherny NI, Sullivan R, Torode J, Saar M, Eniu A. ESMO international consortium study on the availability, out-of-pocket costs and accessibility of antineoplastic medicines in countries outside of Europe. Ann Oncol. 2017; 28:2633-47.

42. Servan-Mori E, Heredia-Pi I, Montañez-Hernandez J, Avila-Burgos L, Wirtz VJ. Access to medicines by Seguro popular beneficiaries: pending tasks towards universal health coverage. PLoS One. 2015;10(9):e0136823. https://doi.org/ 10.1371/journal.pone.0136823.

43. Niëns LM, Cameron $A$, van de Poel $E$, Ewen M, Brouwer WBF, Laing R. Quantifying the impoverishing effects of purchasing medicines: a crosscountry comparison of the affordability of medicines in the developing world. PLoS Med. 2010;7

44. Knaul FM, Arreola-Ornelas H, Méndez-Carniado O, Bryson-Cahn C, Barofsky J, Maguire $R$, et al. Evidence is good for your health system: policy reform to remedy catastrophic and impoverishing health spending in Mexico. Lancet. 2006;368:1828-41.

45. Dorantes-Acosta E, Zapata-Tarrés M, Liliana Miranda-Lora A, Reyes-López A, Muñoz Hernández O, Cortés-Gallo G, et al. Apoyo de organizaciones no gubernamentales a pacientes pediátricos con leucemia linfoblástica aguda afiliados al Seguro popular en México [support from nongovernmental organizations to pediatric patients with acute lymphoblastic leukemia affiliated with the Seguro popular in Mexico]. Bol Med Hosp Infant Mex. 2012;69:212-7.

46. Moye-Holz D, van Dijk JP, Reijneveld SA, Hogerzeil HV. Policy approaches to improve availability and affordability of medicines in Mexico - an example of a middle income country. Global Health. 2017;13:53.

47. O'she Cuevas GJ. LINEAMIENTOS para la adquisición de medicamentos asociados al Catálogo Universal de Servicios de Salud y al Fondo de Protección contra Gastos Catastróficos, por las entidades federativas con recursos transferidos por concepto de cuota social y de la aport. Mexico: Diario Oficial de la Federación; 2016. p. 38

48. Gómez-Dantés $\mathrm{O}$, Wirtz VJ, Reich MR, Terrazas P, Ortiz M. A new entity for the negotiation of public procurement prices for patented medicines in Mexico. Bull World Health Organ. 2012;90:788-92.

49. Knaul FM, González-Pier E, Gómez-Dantés O, García-Junco D, ArreolaOrnelas H, Barraza-Lloréns $M$, et al. The quest for universal health coverage: achieving social protection for all in Mexico. Lancet. 2012;380(9849):1259-79. https://doi.org/10.1016/S0140-6736(12)61068-X.

50. Wirtz VJ, Dreser AC. Alliance for Health Policy and Systems Research flagship report 2014. Medicines in Universal Health Care Coverage. Case Study of
Seguro Popular in Mexico. AHPSR Flagsh Rep. 2014. Chapter 3, Annex 4 pages 11.

51. Moïse P, Docteur E. Pharmaceutical Pricing and Reimbursement Policies in Mexico. Paris: OECD Publishing; 2007.

52. Tobar F, Charreau J. Comparación internacional del precio de los medicamentos de alto costo. Argentina, Países del Cono Sur, España e Inglaterra [International comparison of the price of high-cost medicines. Argentina, Southern Cone Countries, Spain and England]. Buenos Aires: Instituto de Estudios sobre Políticas de Salud; 2011.

53. Hernández-Ávila JE, Palacio-Mejía LS, González-González L, Morales-Carmona E, Espín-Arellano LI, Fernández-Niño JA, et al. Utilization of hospital services for cancer care in Mexico. Salud Publica Mex. 2016;58:142-52.

54. IMS Health. Pharmaceutical market Mexico. Cham: IMS A.G.; 2011.

55. Wirtz VJ, Hogerzeil HV, Gray AL, Bigdeli M, de Joncheere CP, Ewen MA, et al. Essential medicines for universal health coverage. Lancet. 2017;389:403-76.

\section{Publisher's Note}

Springer Nature remains neutral with regard to jurisdictional claims in published maps and institutional affiliations.

Ready to submit your research? Choose BMC and benefit from:

- fast, convenient online submission

- thorough peer review by experienced researchers in your field

- rapid publication on acceptance

- support for research data, including large and complex data types

- gold Open Access which fosters wider collaboration and increased citations

- maximum visibility for your research: over $100 \mathrm{M}$ website views per year

At BMC, research is always in progress.

Learn more biomedcentral.com/submissions 